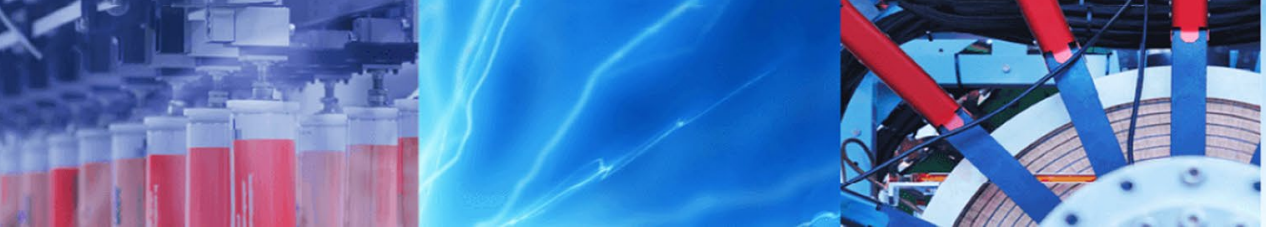

Research Article

\title{
Immobilization of Pt nanoparticles on magnetite-poly (epoxyamine) nanocomposite for the reduction of $p$-nitrophenol
}

\author{
Kannappan Lakshmi ${ }^{1} \cdot$ Rajmohan Rangasamy $^{1}$ (D) E. Prathibha ${ }^{1} \cdot$ A. Sridhar ${ }^{1}$
}

(c) Springer Nature Switzerland AG 2019

\begin{abstract}
Recently the magnetic nanoparticle earns more attention in the field of catalysis for their enhanced loading capacity and magnetic recylability. In this study, we intended to focus the synthesis of polymer coated iron oxide nanoparticle as support for the immobilization of metal nanoparticles. The typical synthetic statergy involves the synthesis of 1,4-diaminobutane functionalized superparamagnetic $\mathrm{Fe}_{3} \mathrm{O}_{4}$ nanoparticle, followed by epoxyamine polymer coating on amine functionalised $\mathrm{Fe}_{3} \mathrm{O}_{4}$ using 1,4 diaminobutane and epichlorohydrin monomers through one pot method. Further, ultrafine Pt nanoparticle was immobilised onto poly (epoxyamine) coated $\mathrm{Fe}_{3} \mathrm{O}_{4}$. These materials were characterized using FT-IR, XRD, VSM, EDS, SEM HRTEM etc. The semiheterogenous catalytic efficiency of the material was examined in aqueous phase reduction of $p$-nitrophenol. The catalyst was reused up to 5 times without loss of activity.
\end{abstract}

\section{Graphic abstract}

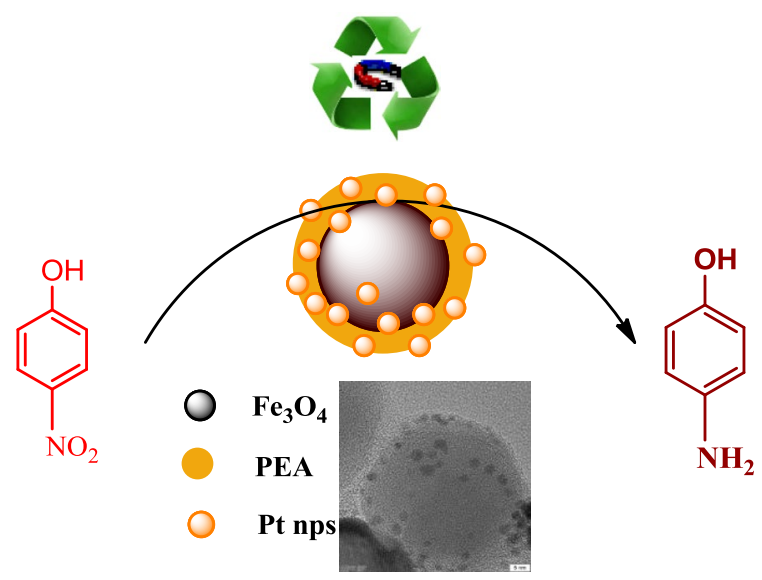

Magnetite-poly (epoxyamine) platinum nanocomposite

Keywords Magnetite $\cdot$ Poly (epoxy amine) $\cdot$ Nanocomposite $\cdot$ Platinum nanoparticle $\cdot$ Immobilization $\cdot$ p-nitrophenol

Rajmohan Rangasamy, rangagncchem@gmail.com | 'Department of Chemistry, Guru Nanak College, Velachery, Chennai, Tamil Nadu 600042, India. 


\section{Introduction}

Magnetic iron oxide nanoparticles being robust with greater surface area have wide spread applications in the field of drug delivery [1], magnetic resonance imaging [2], storage devices [3], catalysis [4] etc. Recently many researchers reported the iron oxide nanoparticle as catalyst support due to their easy recoverability by magnetic separation method [5]. Generally, $\mathrm{Fe}_{3} \mathrm{O}_{4}$ nanoparticles can be synthesized from iron precursors by various method such as chemical reduction, coprecipitation, thermal decomposition, sonochemical method etc. [6]. But while synthesizing $\mathrm{Fe}_{3} \mathrm{O}_{4}$ few factors to be considered like particle size, uniform shape, less aggregation, fine dispersion etc. Numerous methods have been developed to synthesis iron oxide nanoparticles by using surfactants $[7,8]$ organic ligands [9], polymers [10], dendrimers [11] as stabilizers. Among these methods, chemical reduction using amines is simple and convenient for the synthesis of $\mathrm{Fe}_{3} \mathrm{O}_{4}$ nanoparticles with enchanced features. [12]. Further, the surface of the iron oxide nanoparticles have functionalized in order to synthesis specific catalysis. The surface modifications of $\mathrm{Fe}_{3} \mathrm{O}_{4}$ nanoparticles can be carried out by using polymer [13], mesoporous silica [14], metals [15], metal oxides [16] etc. Besides, polymer coating strategy on the $\mathrm{Fe}_{3} \mathrm{O}_{4}$ nanoparticles facilitates numerous sites for further modification and fine dispersion. Many organic polymers such as polyester [17], polyethylene glycol [18], poly styrene [19] etc,. have been reported which forms an organic shell around the iron oxide nanoparticles. These polymer matrix provides an avenue to immobilize metal nanoparticles for catalysis [20]. Normally, metal nanoparticles can be immobilized on the polymer coated iron oxide nanoparticles by following two strategies i.e. to deposit presynthesized metal nanoparticles on the polymer coated iron oxide nanoparticle, but the metal nanoparticles can be leached after catalysis. The second method is to directly grow the metal nanoparticle on the polymeric surface with controllable size. Since polymer possess greater multifunctional atoms and favorable structural features, it provides excellent support for direct synthesis of size-controlled metal nanoparticles. Recently, noble metals such as silver, gold, platinum, palladium nanoparticles were immobilized on solid-support and used for the reduction of $p$-nitrophenol. As we are aware that $p$-nitrophenol is a significant compound in pharma sector and which remains as pollutant too. Hence, it has to be reduced to $p$-aminophenol by greener method in aqueous medium using recoverable and reusable catalysts [21-23].

In this research work, we have demonstrated the efficient two step synthetic protocol for immobilization of platinum nanoparticle onto spherical magnetite-poly (epoxyamine) nanocomposite with uniform size, shape and monodispersion of Pt nanoparticles. Efficacy of this material has been tested for aqueous phase catalysis of reduction of $p$-nitrophenol to $p$-aminophenol.

\section{Experiment and methods}

\subsection{Materials}

Ferrous sulphate heptahydrate $\left(\mathrm{FeSO}_{4} \cdot 7 \mathrm{H}_{2} \mathrm{O}\right), 1,4$-diaminobutane (DAB), epichlorohydrin, sodium borohydride $\left(\mathrm{NaBH}_{4}\right), p$-nitrophenol were purchased from SRL. Chloroplatinic acid $\left(\mathrm{H}_{2} \mathrm{PtCl}_{6}\right)$ was purchased from Sigma Aldrich. Double Distilled (DD) water was used wherever necessary. Reactions were carried out using Remi mechanical overhead stirrer provided with Teflon blade.

\subsection{Characterization methods}

Images were taken using High Resolution Transmission Electron Microscope (HRTEM), JEOL Japan JEM 2100 at $200 \mathrm{kV}$ model with $\mathrm{LaB}_{6}$ electron gun. The grid was placed under electron beam and images were captured. X-ray diffraction patterns were recorded in Bruker USA D8 Advance, Davinci using CuKa radiations with wavelength $0.154 \mathrm{~nm}$. The measurements were made between the angles $10^{\circ}$ and $70^{\circ}$. Magnetic behavior of the nanocomposite materials synthesized were analyzed by using Vibrating Sample Magnetometer Lakshore, 7410 series with a maximum field of 3.1 Testla at room temperature having field setting resolution of $30 \mathrm{mOe}$. FTIR spectra was obtained from Perkin Elmer instrument in transmittance mode for measurements in the range of $4100-400 \mathrm{~cm}^{-1}$ using $\mathrm{KBr}$ pellets sampling method.

\subsection{Synthesis of poly (epoxyamine) functionalized $\mathrm{Fe}_{3} \mathrm{O}_{4}$ nanocomposite $\left(\mathrm{Fe}_{3} \mathrm{O}_{4} / \mathrm{PEA}\right)$}

$0.278 \mathrm{~g}(1 \mathrm{mM})$ of $\mathrm{FeSO}_{4} \cdot 7 \mathrm{H}_{2} \mathrm{O}$ was dissolved in DD water and stirred vigorously. To this solution, about 10 equivalence i.e. $0.8 \mathrm{~mL}$ of DAB $(10 \mathrm{mM})$ was added under continuous stirring, the solution turned green. This suspension turned black when heated at $80^{\circ} \mathrm{C}$ for $6 \mathrm{~h}$. The black particles $\mathrm{Fe}_{3} \mathrm{O}_{4}-\mathrm{NH}_{2}$ got attracted towards magnet [7]. To the above $\mathrm{Fe}_{3} \mathrm{O}_{4}-\mathrm{NH}_{2}$ black suspension, equal amount of $D A B$ $(2 \mathrm{~mL}, 20 \mathrm{mM})$ and epichlorohydrin $(1.6 \mathrm{~mL}, 20 \mathrm{mM})$ were added and stirred at $80^{\circ} \mathrm{C}$ for $24 \mathrm{~h}$ [24]. Magnetite-poly (epoxyamine) nanocomposite obtained was separated by external magnet and washed thrice with DD water, thrice with acetone and dried in vacuum for $24 \mathrm{~h}$. 


\subsection{Immobilization of Pt nanoparticles on $\mathrm{Fe}_{3} \mathrm{O}_{4}$ $\mathrm{PEA}$ nanocomposite $\left(\mathrm{Fe}_{3} \mathrm{O}_{4} / \mathrm{PEA} / \mathrm{Pt}\right)$}

$100 \mathrm{mg}$ of the $\mathrm{Fe}_{3} \mathrm{O}_{4} / \mathrm{PEA}$ nanocomposite was suspended in $50 \mathrm{~mL}$ DD water, to this suspension $0.2 \mathrm{~mL}$ of chloroplatinic acid $(4.8 \mu \mathrm{M})$ were added under continuous stirring for 15 min. Then $\mathrm{Pt}^{4+}$ was reduced with aqueous $\mathrm{NaBH}_{4}$ ( $2.4 \mathrm{mM}, 91 \mathrm{mg}$ ) in cold condition, stirring was continued for $30 \mathrm{~min}$ at room temperature. $\mathrm{Fe}_{3} \mathrm{O}_{4} / \mathrm{PEA} / \mathrm{Pt}$ nanoparticles obtained was washed thrice with DD water, thrice with acetone and dried in vacuum for $24 \mathrm{~h}$.

\subsection{Determination of amine concentration by conductometric titration method}

Exactly $10 \mathrm{mg}$ of the nanomaterial was dispersed in $20 \mathrm{~mL}$ of standardized hydrochloric acid (1 mmol) and stirred mechanically for $30 \mathrm{~min}$. Afterwards, the nanomaterial was isolated by magnetic separation, $5 \mathrm{~mL}$ of supernatant solution was titrated against standardized $\mathrm{NaOH}$ solution, the variations of conductance was measured for each $0.2 \mathrm{~mL}$ addition of $\mathrm{NaOH}$ solution. From the measured conductance, the value of concentration of $\mathrm{HCl}$ remaining in the solution which were not absorbed by the $\mathrm{Fe}_{3} \mathrm{O}_{4} / \mathrm{PEA} / \mathrm{Pt}$ nanocomposite was determined. Henceforth, $\mathrm{HCl}$ consumed by the nanomaterial can be determined and that is equivalent to the concentration of amine groups available on the nanocomposite material.

\subsection{Catalysis of reduction of $p$-nitrophenol}

$1 \mathrm{mM}$ of $p$-nitrophenol solution was stirred with $7 \mathrm{mg}$ of $\mathrm{Fe}_{3} \mathrm{O}_{4} / \mathrm{PEA} / \mathrm{Pt}$ catalyst at room temperature. $10 \mathrm{mM}$ of $\mathrm{NaBH}_{4}$ was added to the above suspension in cold condition under continuous stirring. During the course of the reaction the light-yellow colored $p$-nitrophenol solution turned intense yellow colored solution, it has faded gradually and turned brown in $21 \mathrm{~min}$. This colour change conformed the conversion of $p$-nitrophenol into p-aminophenol.

\section{Results and discussion}

Synthesis of $\mathrm{Pt}$ nanoparticle immobilised $\mathrm{Fe}_{3} \mathrm{O}_{4}$ poly (epoxyamine) nanocomposite was obtained from convenient one-step synthetic protocol. Initially, amine stabilized $\mathrm{Fe}_{3} \mathrm{O}_{4}$ nanoparticle was synthesized from the reduction of $\mathrm{FeSO}_{4}$ using $\mathrm{DAB}$ in the ratio 1:10. DAB acts as the reducer as well as stabilizer to afford spherical shaped monodispersed diamino butane protected $\mathrm{Fe}_{3} \mathrm{O}_{4}$ nanoparticles. Further, the presence of amino groups on the $\mathrm{Fe}_{3} \mathrm{O}_{4}$ nanoparticles provides added advantage for polymer functionalization on it. Additionally, DAB is one of the monomers for the polymer functionalization on iron oxide nanoparticles. Hence, removal of excess DAB has not been implemented and then equimole of $D A B$ and epichlorohydrin were added to the diamine stabilized $\mathrm{Fe}_{3} \mathrm{O}_{4}$ nanoparticles, which was allowed to undergo polycondensation for a period of $24 \mathrm{~h}$ to yield poly (epoxyamine) functionalized magnetite nanocomposite.

Polymer functionalization on the $\mathrm{Fe}_{3} \mathrm{O}_{4}$ nanoparticle protects the iron oxide core from chemical degradation, prevents agglomeration, to enhance the spherical morphology and to achieve well dispersibility in solvents. Besides, the magnetic property of $\mathrm{Fe}_{3} \mathrm{O}_{4}$, also preserved to exhibit the material for high throughput application especially as recyclable catalyst support. Subsequently, Pt nanoparticles were immobilized on the $\mathrm{Fe}_{3} \mathrm{O}_{4} / \mathrm{PEA}$ nanocomposite by a simple wet impregnation method. The actual formation of $\mathrm{Pt}$ nanoparticle was taken place while mixing the $\mathrm{H}_{2} \mathrm{PtCl}_{6}$ with magnetite-poly (epoxyamine) composites, which enables chemical interaction between $\mathrm{Pt}^{4+}$ and amine group. The $\mathrm{Pt}^{4+}$ coordinated to the amine was reduced to $\mathrm{Pt}^{0}$ by means of aq. $\mathrm{NaBH}_{4}$ solution to produce Pt nanoparticle decorated magnetite-poly (epoxyamine) composite. The precise size and uniform distribution of the Pt nanoparticle on the surface of the nanocomposite was attributed by effective stabilization of Pt nanoparticles on polymer functionalized magnetite particles (Scheme 1).

The formation of iron oxide nanoparticles and the presence of amino groups on their periphery has been confirmed primarily through FTIR spectrum (Fig. 1A). Absorbance band around $580 \mathrm{~cm}^{-1}$ attributes for $\mathrm{Fe}-\mathrm{O}$ vibrations of $\mathrm{Fe}_{3} \mathrm{O}_{4}$ and absorbance around $3350 \mathrm{~cm}^{-1}$ attributes to the $-\mathrm{NH}$ stretching, $1625 \mathrm{~cm}^{-1}$ attributes to the $-\mathrm{NH}$ bending of the amine present on the periphery of the iron oxide nanoparticle. The $\mathrm{X}$-ray diffraction pattern of amine stabilized iron oxide nanoparticle has been proved to be magnetite (inverse spinel cubic structure) showing sharp peaks for $2 \theta$ values at $30.25^{\circ}, 35.66^{\circ}, 45.34^{\circ}, 57.37^{\circ}, 62.7^{\circ}$ corresponds to the respective lattice planes (220), (311), (400), (511), (440) (Fig. 2A). These XRD patterns matched well with JCPDS patterns of magnetite (JCPDS card No. 19-0629). The magnetic behavior of the synthesized amine stabilized $\mathrm{Fe}_{3} \mathrm{O}_{4}$ nanoparticles were evidenced to be superparamagnetic through the VSM studies (Fig. 3A). These nanoparticles acquired magnetic saturation value of $68.8 \mathrm{emu} / \mathrm{g}$ even when high magnetic field in the order of 1500 KOe was applied. Additionally, these nanoparticles have less magnetic retentivity such that negligible hysteresis loop was observed. Thus, the magnetometry studies authorizes the amine stabilized $\mathrm{Fe}_{3} \mathrm{O}_{4}$ nanoparticles behaves like temporary magnet which acquires magnetic moment only in the presence of an external magnet. The 
Scheme 1 Synthesis of $\mathrm{Pt}$ nanoparticle decorated on magnetite-poly (epoxyamine) nanocomposite
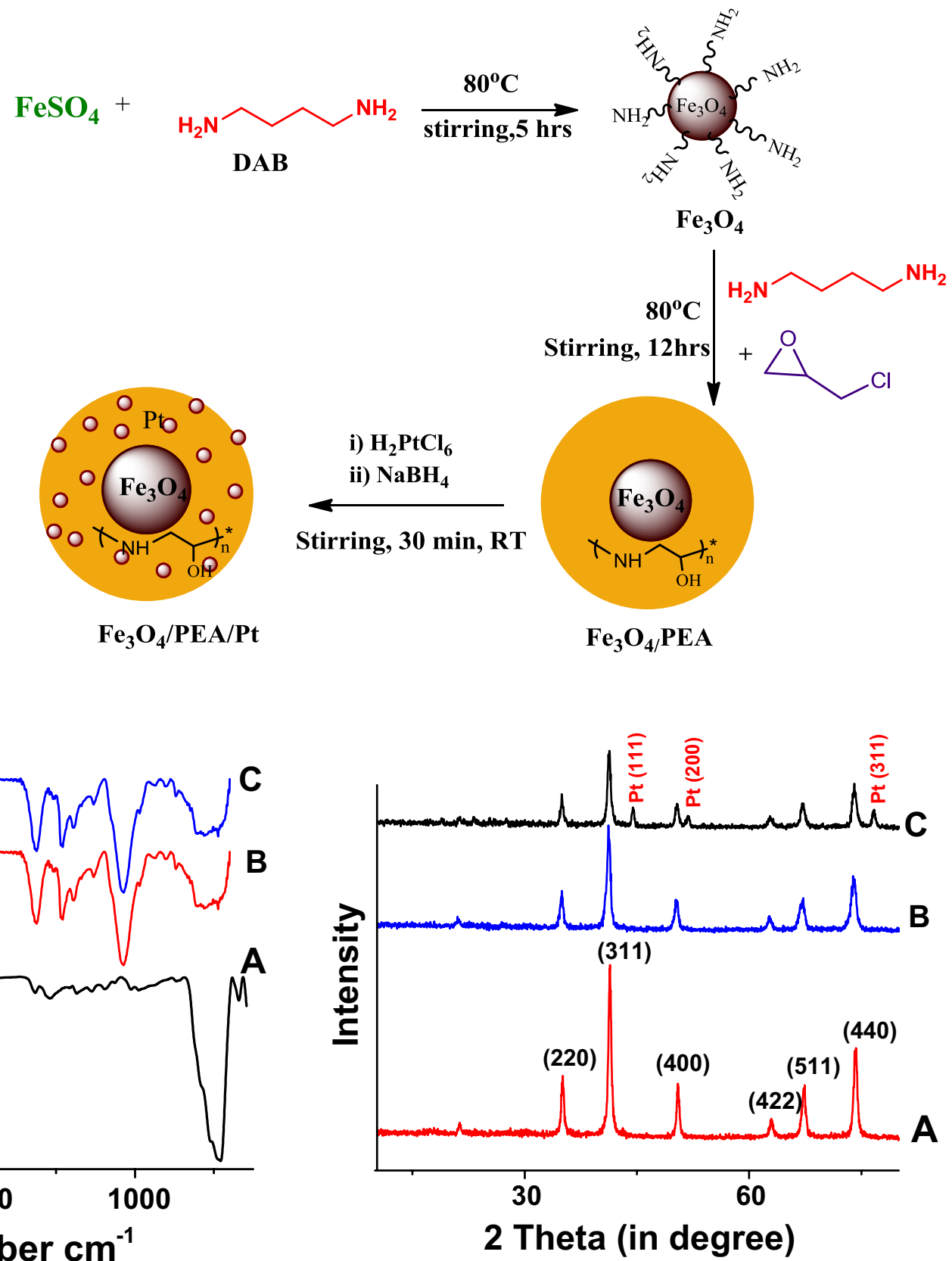

Fig. 2 X-ray diffraction patterns of (A) $\mathrm{Fe}_{3} \mathrm{O}_{4}$ nanoparticle, (B) $\mathrm{Fe}_{3} \mathrm{O}_{4} / \mathrm{PEA}$ nanocomposite, (C) $\mathrm{Fe}_{3} \mathrm{O}_{4} / \mathrm{PEA} / \mathrm{Pt}$ nanocomposite

agglomeration (Fig. 4a), since the $\mathrm{Fe}_{3} \mathrm{O}_{4}$ nanoparticle were stabilized with $\mathrm{DAB}$. These observations of amine stabilized $\mathrm{Fe}_{3} \mathrm{O}_{4}$ nanoparticle were further confirmed from HRTEM images (Fig. 5a). The size of the nanoparticles was found to be around $35 \pm 5 \mathrm{~nm}$ from HRTEM images, which holds in good agreement with the size calculated from XRD from Scherrer formula. The FWHM was determined for 311 lattice plane and the crystallite size of the magnetite nanoparticle was calculated from 


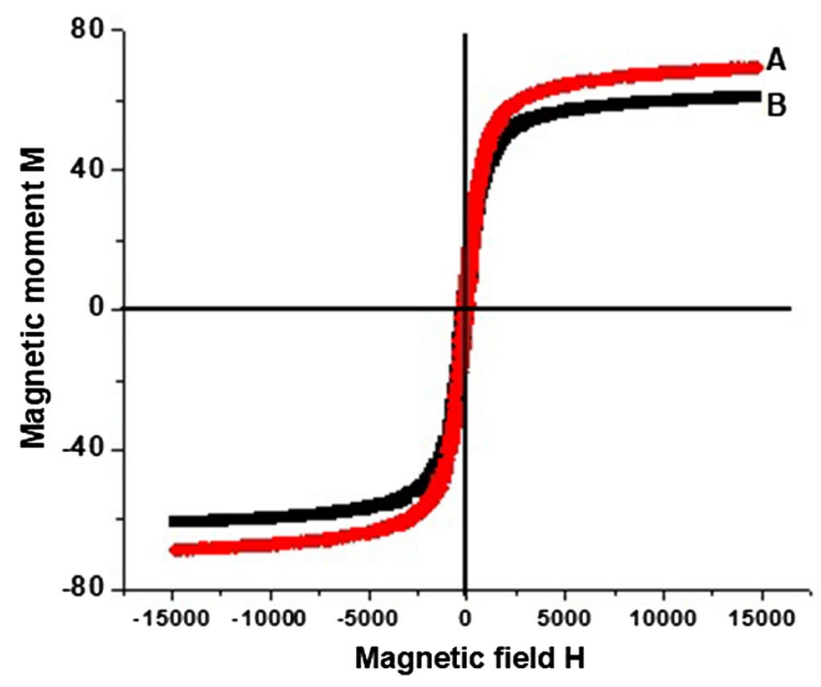

Fig. 3 VSM studies of (A) $\mathrm{Fe}_{3} \mathrm{O}_{4}$ nanoparticle, (B) $\mathrm{Fe}_{3} \mathrm{O}_{4}$ /PEA nanocomposite

the Scherrer equation $D=\left(K{ }^{*} \lambda\right) /(\beta * \cos \theta)$ where $K=0.69$, $\lambda=$ wavelength of $X$-ray, $\beta=F W H M$.

$\mathrm{Fe}_{3} \mathrm{O}_{4} / \mathrm{PEA}$ nanocomposite material was synthesized by the condensation polymerization of $D A B$ and epichlorohydrin on amine stabilized $\mathrm{Fe}_{3} \mathrm{O}_{4}$ nanoparticle. It was confirmed through FTIR (Fig. 1B) from increased intensity of absorption band around $3350 \mathrm{~cm}^{-1}$ for $-\mathrm{NH}$ as well as $-\mathrm{OH}$ stretching, appearance of new band at $3250 \mathrm{~cm}^{-1}$ for $-\mathrm{CH}$ stretching and decreased intensity of absorption band at $580 \mathrm{~cm}^{-1}$ for $\mathrm{Fe}-\mathrm{O}$ vibration due to functionalization of PEA on iron oxide nanoparticles compared with the FTIR spectrum obtained for amine stabilized $\mathrm{Fe}_{3} \mathrm{O}_{4}$ nanoparticle. Hence, these absorption band depicts that the formation of $\mathrm{Fe}_{3} \mathrm{O}_{4} / \mathrm{PEA}$ nanocomposite. The XRD pattern for $\mathrm{Fe}_{3} \mathrm{O}_{4} / \mathrm{PEA}$ nanocomposite does not show any new characteristic peak other than the patterns observed for magnetite nanoparticle, confirming that the magnetite crystallite structure has not been disturbed even after polymer functionalization (Fig. 2B). In addition to these analytical observations, VSM study validates the persistence of superparamagnetic character of $\mathrm{Fe}_{3} \mathrm{O}_{4} / \mathrm{PEA}$ nanocomposite. The observed magnetic saturation values for $\mathrm{Fe}_{3} \mathrm{O}_{4}$ and $\mathrm{Fe}_{3} \mathrm{O}_{4} / \mathrm{PEA}$ is $68.8 \mathrm{emu} / \mathrm{g}$ and $60.2 \mathrm{emu} / \mathrm{g}$ respectively. The decline in magnetic saturation values from 68.8 to $60.2 \mathrm{emu} / \mathrm{g}$ provides the insight information about the polymer functionalization of magnetite nanoparticle (Fig. 3B). Moreover, the superparamagnetic behavior still exists favoring the easy recoverability of the nanoparticle by using external magnet. The polymer functionalization on $\mathrm{Fe}_{3} \mathrm{O}_{4}$ nanoparticle was also observed from HRTEM images (Fig. 5b). Independent $\mathrm{Fe}_{3} \mathrm{O}_{4} / \mathrm{PEA}$ nanocomposite were found, having boundary for each entity of $\mathrm{Fe}_{3} \mathrm{O}_{4} / \mathrm{PEA}$ nanocomposite. The diamine present on iron oxide nanoparticles serves as monomer and it facilitates the polymerization with epichlorohydrin on $\mathrm{Fe}_{3} \mathrm{O}_{4}$ nanoparticle consistently, such that they appear to be monodispersed with less agglomeration.

As discussed earlier, Pt nanoparticle were immobilized on $\mathrm{Fe}_{3} \mathrm{O}_{4} / \mathrm{PEA}$ via coordination of $\mathrm{Pt}^{4+}$ with amino group of the polymer followed by reduction of $\mathrm{Pt}^{4+}$ to
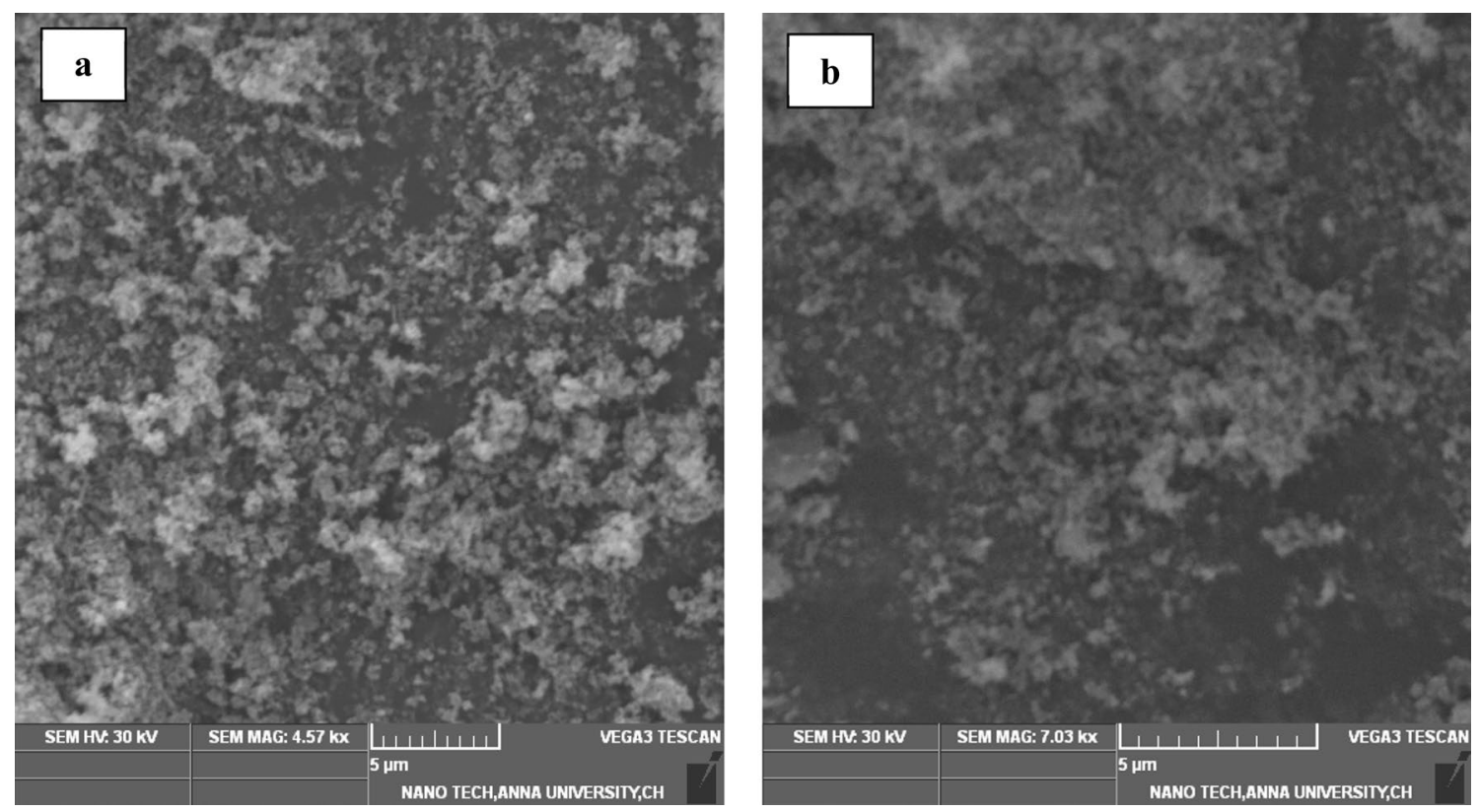

Fig. 4 SEM images of $\mathbf{a ~ F e} \mathrm{O}_{4}$ nanoparticle, $\mathbf{b} \mathrm{Fe}_{3} \mathrm{O}_{4} / \mathrm{PEA}$ nanocomposite 

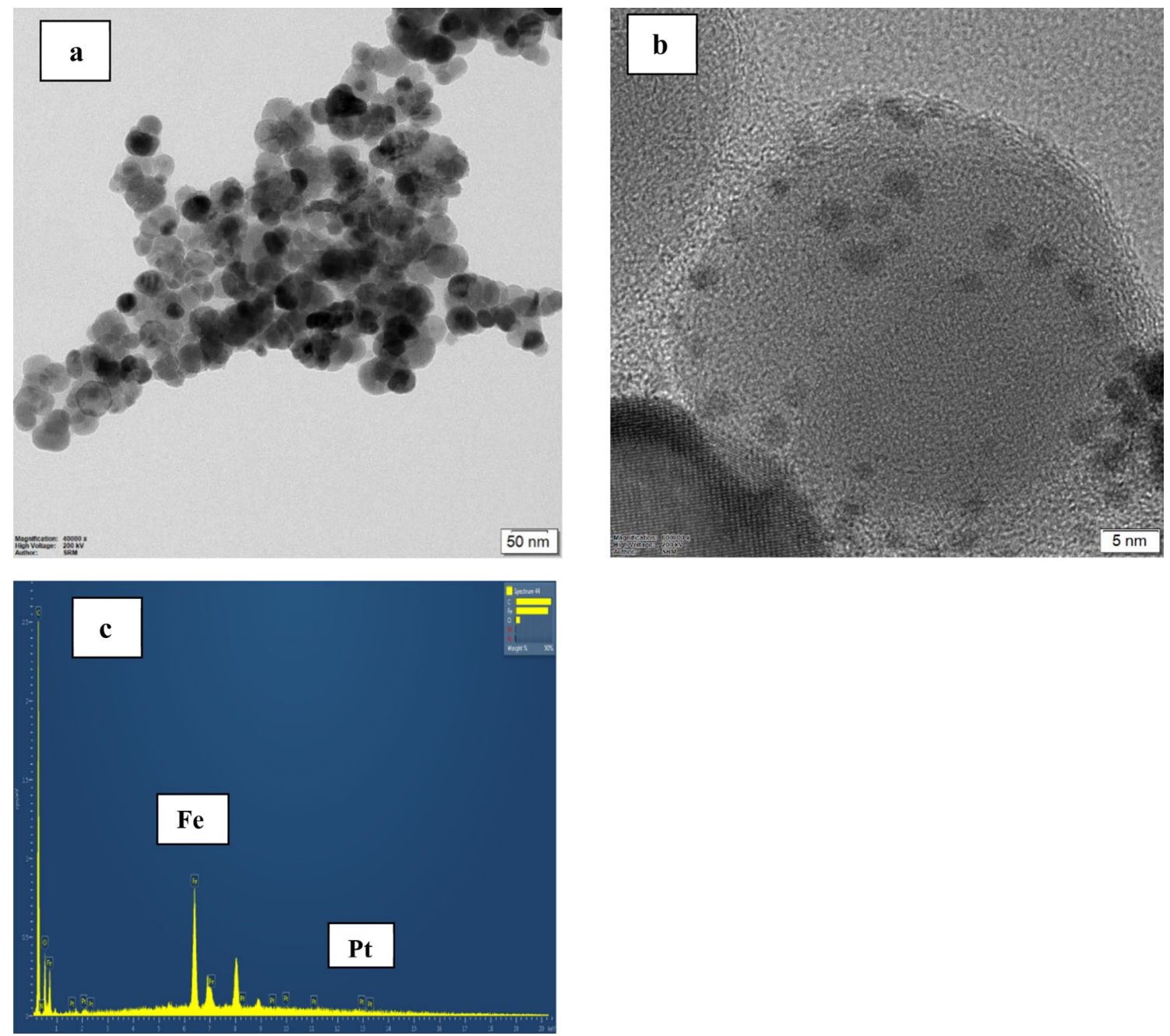

Fig. 5 HRTEM images of $\mathbf{a ~} \mathrm{Fe}_{3} \mathrm{O}_{4} / \mathrm{PEA}$ nanocomposite, $\mathbf{b} \mathrm{Fe}_{3} \mathrm{O}_{4} / \mathrm{PEA} / \mathrm{Pt}$ nanocomposite, $\mathbf{c}$ EDS spectrum of Fe $\mathrm{O}_{4} / \mathrm{PEA} / \mathrm{Pt}$ nanocomposite

$\mathrm{Pt}^{0}$ using aq. $\mathrm{NaBH}_{4}$. Pt nanoparticles were evenly distributed on the surface of the $\mathrm{Fe}_{3} \mathrm{O}_{4} / \mathrm{PEA}$ nanocomposite that can be attributed due to the presence of more availability of functional atoms such as nitrogen and oxygen available on the polymer stabilizes the metal nanoparticle. The Pt nanoparticles immobilized on the matrix was confirmed from the XRD pattern obtained for $\mathrm{Fe}_{3} \mathrm{O}_{4} / \mathrm{PEA} / \mathrm{Pt}$ nanocomposite which showed new peak for platinum crystal structure for the lattice plane $111,200,311$ and this in addition to the magnetite crystallite lattice planes [25]. Further, HRTEM images envisages $\mathrm{Fe}_{3} \mathrm{O}_{4} / \mathrm{PEA}$ nanoparticle entity contains ultrafine $\mathrm{Pt}$ nanoparticle that additionally supports the increase in loading capacity of the polymer (Fig. $5 \mathrm{c}$ ). Hence, the synthesized $\mathrm{Fe}_{3} \mathrm{O}_{4} / \mathrm{PEA} / \mathrm{Pt}$ nanocomposite will serve as better catalyst for reduction reactions.

\section{Catalysis}

\subsection{Reduction of $p$-nitrophenol to $p$-aminophenol using $\mathrm{Fe}_{3} \mathrm{O}_{4} / \mathrm{PEA} / \mathrm{Pt}$ nanocomposite}

The catalytic activity examination of $\mathrm{Fe}_{3} \mathrm{O}_{4} / \mathrm{PEO} / \mathrm{Pt}$ nanocomposite was evaluated for the reduction reaction of $p$-nitrophenol to $p$-aminophenol (Scheme 2). Usually,

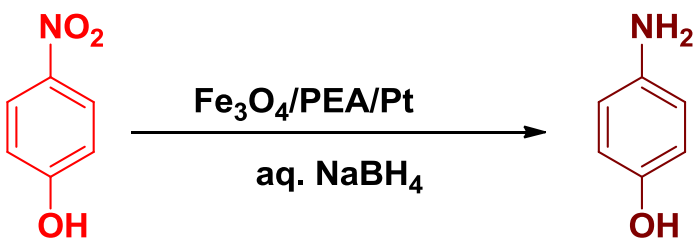

Scheme 2 Reduction of $p$-nitrophenol to $p$-amino phenol 
Palladium and gold nanoparticles were employed for various reduction reactions. Platinum metal being stable and inert, it was chosen for immobilization on magnetic nanoparticle support in order to carry out the reduction reaction of $p$-nitrophenol to $p$-aminophenol which has been the major source for preparation of paracetamol. In normal practice $p$-Nitrophenol does not undergo reduction reaction with $\mathrm{NaBH}_{4}$ in the absence of catalyst. Therefore the $\mathrm{Fe}_{3} \mathrm{O}_{4} / \mathrm{PEA} / \mathrm{Pt}$ was used as semiheterogenous catalyst of activate $\mathrm{NaBH}_{4}$ and $p$-nitrophenol which inturn facilitates the reduction reaction with much faster rate. Since the particle size of the catalyst is in nanodimension, it is easily dispersed in reaction medium and leads to semiheterogenous phase catalyst. The yellow colored solution started to fade and turned brown at $20 \mathrm{~min}$, which indicated the reduction of $p$-nitrophenol to $p$-aminophenol. Further, the conversion of products was confirmed through UV-Vis absorption measurement, $p$-nitrophenol showed absorbance spectrum at $400 \mathrm{~nm}$ for the protonation of $\mathrm{p}$-nitrophenolate ion with aq. $\mathrm{NaBH}_{4}$. After the addition of the catalyst, absorption peak at $400 \mathrm{~nm}$ was diminished and disappeared after $20 \mathrm{~min}$, that infers the complete reduction of $p$-nitrophenol to $p$-aminophenol (Fig. 6). Finally, the $\mathrm{Fe}_{3} \mathrm{O}_{4} / \mathrm{PEO} / \mathrm{Pt}$ nanocatalyst was separated by magnetic attraction and regenerated by washing thrice with water, acetone and dried (Fig. 7). The recycling efficiency of the regenerated catalyst was tested up to five cycles. The catalyst showed remarkable efficiency even after fifth cycle for reduction of $p$-nitrophenol, without any significant loss in catalytic activity and loss in weight of the catalyst also.

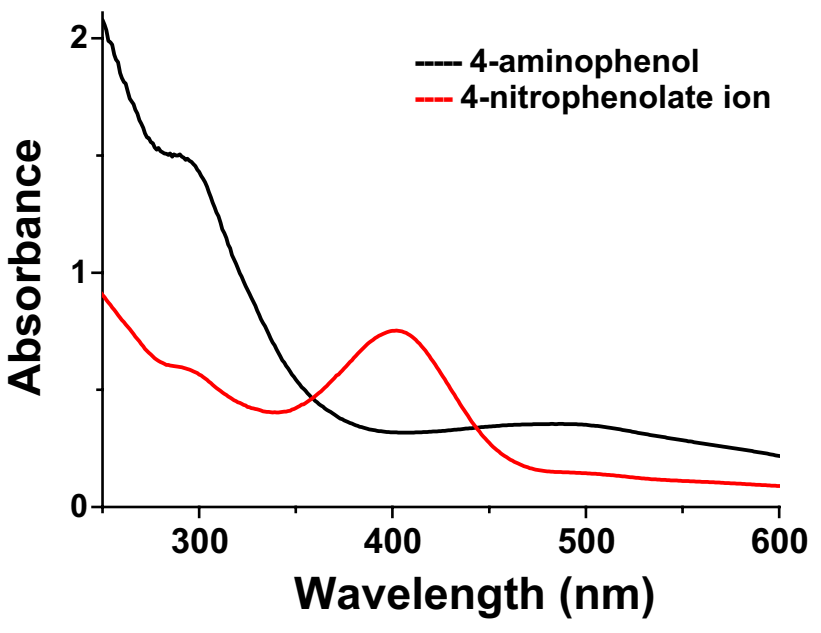

Fig. 6 UV-Vis absorbance for the reduction of $p$-nitrophenol to $p$-aminophenol

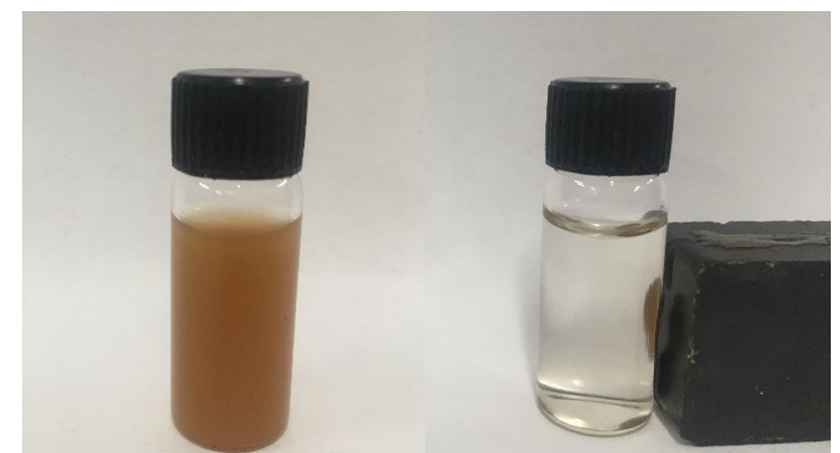

Fig. 7 Photograph for the magnetic separation of the $\mathrm{Fe}_{3} \mathrm{O}_{4} / \mathrm{PEA} / \mathrm{Pt}$ nanocomposite

\subsection{Mechanism for the catalytic reduction of $p$-nitrophenol}

The actual mechanism for the reduction of $p$-nitrophenol using platinum nanoparticle immobilized on poly (epoxyamine) coated iron oxide nanoparticle catalyst has described in Scheme 3. The typical mechanism involves the steps such as (I) adsorption of the borohydride anion and $p$-nitrophenol on the surface of the platinum nanoparticle, (II) formation of $p$-nitrosophenol, (III) formation of $p$-hydroxyaminophenol, (IV) hydride transfer for the formation of $p$-aminophenol compound, $(\mathrm{V})$ desorption of the product $p$-aminophenol and borohydride ions [26, 27].

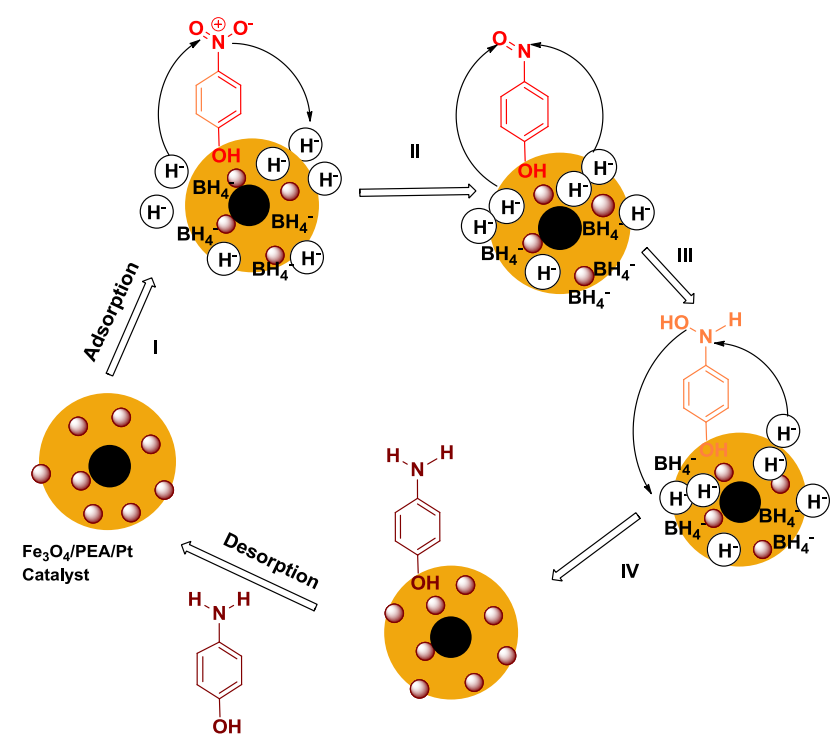

Scheme 3 Proposed mechanism for the catalytic reduction of $p$-nitrophenol to $p$-aminophenol 


\section{Conclusion}

We have successfully demonstrated the one-pot synthesis of magnetite-poly (epoxyamine) nanocomposite with controlled particle size, uniform shape and fine dispersion. Platinum nanoparticles were decorated onto magnetic polymer matrix. The synthesized nanocomposite was proved to be an efficient catalyst for the reduction of $p$-nitrophenol, also the recycle efficiency of catalyst was examined up to five cycles without any significant loss of their catalytic activity. Hence, the nanocomposite material will replace the existing catalyst for reduction reactions in industries and further many organic transformations can be achieved.

Acknowledgements RR thank SERB, India for financial support (EEQ/2017/000374). We dedicate this research work to our beloved teacher Dr. M. Selvaraj, Principal, Guru Nanak College. We acknowledge HRTEM facility at SRMIST set up with support from MNRE (Project No. 31/03/2014-15/PVSE-R\&D), Gol. Analytical facilities rendered from IIT Kanpur, IIT Guwahati, MNIT Jaipur are gratefully acknowledged.

\section{Compliance with ethical standards}

Conflict of interest On behalf of all authors, the corresponding author states that there is no conflict of interest.

\section{References}

1. Yoon HJ, Lim TG, Kim JH et al (2014) Fabrication of multifunctional layer-by-layer nanocapsules toward the design of theragnostic nanoplatform. Biomacromolecules 15:1382-1389. https://doi.org/10.1021/bm401928f

2. Joseph A, Villaraza L, Bumb A, Brechbiel MW (2010) Macromolecules, dendrimers, and nanomaterials in magnetic resonance imaging: the interplay between size, function, and pharmacokinetics. Chem Rev 110:2921-2959. https://doi.org/10.1021/ cr900232t

3. Wang $\mathrm{Q}$, Jiao $\mathrm{L}$, Du H et al (2014) $\mathrm{Fe}_{3} \mathrm{O}_{4}$ nanoparticles grown on graphene as advanced electrode materials for supercapacitors. J Power Sources 245:101-106. https://doi.org/10.1016/j. jpowsour.2013.06.035

4. Baig NBR, Varma RS (2013) Magnetically retrievable catalysts for organic synthesis. Chem Commun 49:752-770. https://doi. org/10.1039/C2CC35663E

5. Shylesh S, Schünemann V, Thiel WR (2010) Magnetically separable nanocatalysts: bridges between homogeneous and heterogeneous catalysis. Angew Chem Int Ed 49:3428-3459. https://doi.org/10.1002/anie.200905684

6. Teja AS, Koh P (2009) Synthesis, properties, and applications of magnetic iron oxide nanoparticles. Prog Cryst Growth Charact Mater 55:22-45. https://doi.org/10.1016/j.pcrys grow.2008.08.003

7. Aslam M, Schultz EA, Sun T et al (2007) Synthesis of amine stabilised aqueous colloidal iron oxide nanoparticles. Cryst Growth Des 7:471-475. https://doi.org/10.1021/cg060656p
8. Liu X, Wang L (2004) A one-pot synthesis of oleic acid endcapped temperature- and $\mathrm{pH}$-sensitive amphiphilic polymers. Biomaterials 25:1929-1936. https://doi.org/10.1016/j.bioma terials.2003.08.023

9. Frankamp BL, Fischer NO, Hong R et al (2006) Surface modification using cubic silsesquioxane ligands. Facile synthesis of water-soluble metal oxide nanoparticles. Chem Mater. https:// doi.org/10.1021/cm052205i

10. Kainz QM, Reiser O (2013) Polymer- and dendrimer-coated magnetic nanoparticles as versatile supports for catalysts, scavengers, and reagents. Acc Chem Res 47:667-677. https://doi. org/10.1021/ar400236y

11. Bronstein LM, Shifrina ZB (2011) Dendrimers as encapsulating, stabilizing, or directing agents for inorganic nanoparticles. Chem Rev 111:5301-5344. https://doi.org/10.1021/cr2000724

12. Wang L, Bao J, Wang L et al (2006) One-pot synthesis and bioapplication of amine-functionalized magnetite. Chem A Eur J 12:6341-6347. https://doi.org/10.1002/chem.200501334

13. Adenier A, Cabet-deliry E, Lalot T, Pinson J (2002) Attachment of polymers to organic moieties covalently bonded to iron surfaces. Chem Mater 14:4576-4585. https://doi.org/10.1021/ $\mathrm{cm} 0211397$

14. Lee J, Lee Y, Youn JK et al (2008) Simple synthesis of functionalized superparamagnetic magnetite/silica core/shell nanoparticles and their application as magnetically separable high-performance biocatalysts. Small 4:143-152. https://doi. org/10.1002/smll.200700456

15. Li J, Zheng L, Cai H et al (2013) Facile one-pot synthesis of $\mathrm{Fe}_{3} \mathrm{O}_{4} @$ Au composite nanoparticles for dual-mode MR/CT imaging applications. ACS Appl Mater Interfaces 5:10357-10366. https://doi.org/10.1021/am4034526

16. Kim LJ, Jang JW, Park JW (2014) $\mathrm{Nano} \mathrm{TiO}_{2}$-functionalized magnetic-cored dendrimer as a photocatalyst. Appl Catal B Environ 147:973-979. https://doi.org/10.1016/j.apcatb.2013.10.024

17. Hazarika A, Deka BK, Kim D et al (2017) Microwave-synthesized freestanding iron-carbon nanotubes on polyester composites of woven Kevlar fibre and silver nanoparticle-decorated graphene. Sci Rep 7:1-11. https://doi.org/10.1038/srep40386

18. Nigam S, Chandra S, Newgreen DF et al (2014) Poly(ethylene glycol)-modified PAMAM- $\mathrm{Fe}_{3} \mathrm{O}_{4}$-doxorubicin triads with the potential for improved therapeutic efficacy: generationdependent increased drug loading and retention at neutral $\mathrm{pH}$ and increased release at acidic $\mathrm{pH}$. Langmuir 30:1004-1011. https://doi.org/10.1021/la404246h

19. Xie $Y$, Sougrat $R$, Nunes SP (2015) Synthesis and characterization of polystyrene coated iron oxide nanoparticles and asymmetric assemblies by phase inversion. J Appl Polym Sci 41368:1-11. https://doi.org/10.1002/app.41368

20. Murugan E, Rangasamy R (2010) Synthesis, characterization, and heterogeneous catalysis of polymer-supported poly(propyleneimine) dendrimer stabilized gold nanoparticle catalyst EAGAMBARAM. J Polym Sci Part A Polym Chem 48:2525-2532. https://doi.org/10.1002/pola.24028

21. Das TK, Bhawal P, Ganguly S et al (2018) A facile green synthesis of amino acid boosted $\mathrm{Ag}$ decorated reduced graphene oxide nanocomposites and its catalytic activity towards 4-nitrophenol reduction. Surf Interfaces 13:79-91. https://doi.org/10.1016/j. surfin.2018.08.004

22. Das TK, Ganguly S, Bhawal P et al (2018) A facile green synthesis of silver nanoparticles decorated silica nanocomposites using mussel inspired polydopamine chemistry and assessment its catalytic activity. J Environ Chem Eng. https://doi.org/10.1016/j. jece.2018.10.067

23. Kanti T, Sayan D, Poushali G et al (2018) Mussel inspired green synthesis of silver nanoparticles-decorated halloysite nanotube using dopamine: characterization and evaluation of its 
catalytic activity. Appl Nanosci. https://doi.org/10.1007/s1320 4-018-0658-3

24. Tepzz T, Reticules PDA (2006) Eur. Pat. EP 1831266 B1 [0001]2010, 1, 1 WO 2006/043984 (27.04.2006 Gazette 2006/17). https://doi.org/10.1007/s42452-019-1137-5

25. Abu-Reziq R, Wang D, Post M, Alper H (2007) Platinum nanoparticles supported on ionic liquid-modified magnetic nanoparticles: selective hydrogénation catalysts. Adv Synth Catal 349:2145-2150. https://doi.org/10.1002/adsc.200700129

26. Das TK, Ganguly S, Remanan S, Ch N (2019) Temperaturedependent study of catalytic Ag nanoparticles entrapped resin nanocomposite towards reduction of 4-nitrophenol. Chem Sel 4:3665-3671. https://doi.org/10.1002/slct.201900470
27. Kariper IA, Oğuzhan $M$, Zafer Ç (2018) Heterogeneous $\mathrm{Au} / \mathrm{Ru}$ hybrid nanoparticle decorated graphene oxide nanosheet catalyst for the catalytic reduction of nitroaromatics. Res Chem Intermed. https://doi.org/10.1007/s11164-018-3644-1

Publisher's Note Springer Nature remains neutral with regard to jurisdictional claims in published maps and institutional affiliations. 